\title{
APUNTES PARA EL ASESORAMIENTO DE LA TESIS UNIVERSITARIA
}

Agustín Campos Arenas

\begin{abstract}
RESUMEN
La asesoría de tesis es una responsabilidad docente que debe ser asumida con los conocimientos disciplinarios y formales para que la elaboración de la tesis sea una realidad. Este artículo presenta los errores comunes en la elaboración de la tesis, los conocimientos básicos formales sobre la tesis que la institución ha adoptado y se concluye con un desarrollo sobre el asesor.
\end{abstract}

\section{PALABRAS CLAVE}

Asesoramiento de tesis, conocimientos básicos del asesor, asesor.

\section{ABSTRACT}

The Thesis advice is a profesor responsability that must be assumed with the formal and disciplinary knowledge in order that the thesis preparation can be achieved. This article presents the common errors during this process, the formal basic knowledge about the dissertation adopted by the institution and concludes with some lines about the advisor.

\section{KEYWORDS}

Thesis advice, advisor's basic knowledge, advisor.
$\mathrm{D}$ e acuerdo al diccionario de la lengua española de la Real Academia, "asesorar" significa "dar consejo o dictamen". Proviene de la palabra latina ASSESSOR, "que era la persona que se sentaba junto al juez y lo aconsejaba a juzgar y sentenciar los casos presentados en la corte" (Diccionario Etimológico). También se le asocia con la palabra "consultoría / consultor" cuya raíz latina es "consultus" que significa asesoramiento. La Real Academia califica al consultor como "la persona experta en una materia que asesora profesionalmente".

Como sinónimos de asesoramiento se mencionan varios. Entre ellos, se encuentran consejo, sugerencia, recomendación, orientación, parecer, aclaración, dirección, encauzamiento, encarrilamiento, etc. Indudablemente, en el proceso de asesorar se realizan varias de estas acepciones (WordReference.com). Es decir, el asesoramiento es un acto dinámico de acciones múltiples.

En nuestro caso se trata de asesoramiento de tesis, la cual debe ser elaborada y sustentada por la estudiante para optar por el título profesional o grado académico en los estudios de pre y posgrado. Es, por lo tanto, un requisito de acuerdo a la ley universitaria peruana.

\section{Error común}

La exigencia antes mencionada está llevando erróneamente a algunas estudiantes a tomar caminos cortos para tener la tesis. Permítanme mencionar brevemente los siguientes: 
1. Comprar una tesis. Han reaparecido las ofertas para elaborar las tesis de cualquier carrera, como lo evidencia la propaganda escrita y la Web. El diario "El Comercio", del 11 de noviembre de 2016, presenta el artículo "El negocio de la tesis: ¿Cuánto te cuesta, cuanto te vale?". Relata la historia de la venta de tesis. Estos "negocios" audazmente, en muchos casos, se ubican a unos pasos de las universidades. Según el diario, los costos varían entre 650 y 2,500 Soles.

Hacer la tesis mediante el plagio. Es una situación de "cut and paste" (corte y pega), no reconociéndose a los autores en las fuentes. La palabra "plagio" ha estado referida al delito de secuestro desde antaño hasta la actualidad. Se menciona, sin embargo, al poeta Marcial (siglo I dC) como el primero al darle el sentido al que ahora, también, se le asocia. Se lamentaba que "otro autor haya adaptado sus obras y que estén en servidumbre" (Historia de Iberia Vieja, 2013).

Plagio es definido por el Diccionario de La Lengua Española de la Real Academia como la "acción de copiar en lo sustancial obras ajenas, dándolas como propias". Es una acción ilícita, pues se pretende suplantar al verdadero autor. En los documentos escritos puede verificarse con rapidez utilizando la tecnología actual.

Al respecto, De Paz (El Comercio 2016) sostiene que, en la SUNEDU, de la cual forma parte: Tuvimos una reunión del consejo directivo y se ha acordado actuar desde la dirección de grados y títulos y exigir a las universidades como una condición básica de calidad, que todas las tesis hayan tenido que pasar por un proceso de verificación de plagio.

Esto implica que las universidades deben contar con el software correspondiente y establecer los mecanismos para que se cumpla con este requisito de calidad. El plagio está penado y para ello existe "los derechos/propiedad intelectual" que son normas en defensa del verdadero autor. Las universidades, por su parte, establecen también sanciones al respecto.

En el mundo intelectual, al plagiario se le representa como una "Corneja desplumada" (corneja, es un ave parecida al cuervo). Cuenta la fábula griega de Esopo (edyd.com) que el Gran Dios Zeus se propuso premiar al ave más hermosa. Todas las aves se prepararon para la competencia, pero la Corneja, que se consideraba fea, recogió coloridas plumas que se desprendían de otras aves y las sobrepuso a las suyas. El resultado fue espectacular. Zeus quedó atónito y a punto de proclamarla como la más bella. En ese momento, las otras aves al reconocer sus plumas se las arrancaron quedando como "corneja desplumada". La lección es "no hagas alarde de bienes ajenos como si fueran propios, pues tarde o temprano el engaño quedará al descubierto".

Hay una serie de casos de plagio. Solo aparecen en los medios aquellos que se refieren a personas que ocupan cargos importantes.

\section{En el Perú}

Un promotor de universidades y candidato presidencial tiene acusaciones de copia en su tesis de Maestría, tesis de Doctorado y publicación de obra de otro autor con su nombre (RPP 2016).

Juez que copió de una tesis de 1999 de otra persona. Tomó 102 páginas para su tesis de maestría (2003) y para publicar un libro (2005) tomó 117 páginas (IDLreporteros 2013).

Un famoso escritor peruano fue acusado de presentar como suyos artículos escritos por otros (El País 2012).

\section{En el extranjero}

...IDl- reporteros (2013) menciona los casos siguientes:

En Alemania, la Ministra de Educación y Ciencia renunció al cargo cuando se supo 
que la Universidad donde estudió, le revocó el grado de Doctora en Filosofía por evidencias de plagio (2013).

En Alemania, el Ministro de Defensa renunció a su cargo al ponerse en evidencia que el $20 \%$ de su tesis doctoral era plagio (2011).

El Presidente de Hungría renunció a la presidencia al descubrirse que plagio parte de su tesis doctoral; algunos medios estimaron que fue cerca del $75 \%$ (2012).

En Ecuador, al Vicepresidente se le acusa de copiar capítulos enteros en su tesis de Licenciatura, de páginas Web tales como "monografías.com" y el "rincón del vago" (2013).

En el periodismo, se ha hecho público los plagios siguientes:-

Una periodista reconocida del Washington Post y ganadora de tres premios Pulitzer, fue suspendida por el diario al comprobarse que había plagiado artículos de otros periodistas (2011). Pidió disculpas por cometer "uno de los pecados imperdonables del periodismo".

Otro respetado periodista es suspendido temporalmente por la revista "Time", el diario "Washington Post" y la Cadena de Televisión CNN por plagio de un artículo publicado en el "The New Yorker". Pidió disculpas y renunció al Consejo de Gobierno de la Universidad de Yale.

También se hizo de conocimiento público:

El plagio de 20 párrafos de un libro en su tesis de Licenciatura (Derecho) del Presidente de México. La Universidad Panamericana hizo el anuncio (Telesur 2016).

En Francia (2011), la más alta autoridad de los judíos en ese país reconoció que en su libro "40 meditaciones judías" había cometido plagio. Pidió disculpas a los autores y renunció al cargo (La República 2016).
La ex Vicepresidenta del Parlamento Europeo, plagió su tesis doctoral. La Universidad de Alemania le retiró su título (ABC.es 2011).

Es obvio que existen miles de casos. Los mencionados aquí son ilustrativos por la importancia del plagiario en el contexto local y/o internacional.

\section{CONOCIMIENTOS BÁSICOS DEL ASESOR}

El trabajo de la tesis y el asesoramiento en investigación requieren del conocimiento, comprensión y dominio de diferentes contenidos. Los asesores y asesorados deben manejarse con solvencia y propiedad en dos contenidos fundamentales. Estos se presentan a continuación:

\section{El protocolo de tesis}

Como primer paso, es necesario que tanto el asesor como la asesorada tengan claro la estructura del documento/informe de la tesis. Pero no solo en su nomenclatura sino, fundamentalmente, en el significado / contenido de cada elemento.

Las facultades de las Universidades deben contar con documentos orientadores al respecto. Por ejemplo, guías que documenten la naturaleza y el propósito de los componentes estructurales del plan/proyecto de tesis y de la tesis misma. Igualmente, los libros que abordan la estructura de la tesis serán de utilidad para esta etapa.

El esquema de tesis es diferente al de un artículo para revista o al de un ensayo. Los esquemas deben ser sometidos a revisión y reajuste para actualizarlos a las nuevas tendencias de investigación y a las posibilidades reales de los estudiantes, según los niveles de estudios. Estas guías y orientaciones deben estar impresas y en la Web, y deber ser dominadas por los docentes y estudiantes. Representan marcos de referencia obligatorios. A través de la Facultad de Ciencias de la Educación publiqué, junto con dos exalumnas que experimentaron el proceso de asesoramiento y culminaron una tesis, el "Manual 
para la estructuración de la tesis universitaria" (Campos y otros 2000), en donde se presenta un esquema que se ilustra a través de ejemplos. También, la Escuela de Posgrado tiene desde hace mucho tiempo (década 1970) un esquema de tesis, el cual fue revisando periódicamente. Las últimas corresponden a los años 2012 y 2015.

Otra buena fuente recomendada para entender los elementos/partes del esquema de tesis lo constituyen las mejores tesis sustentadas. Allí, se encuentran ejemplos auténticos de cómo se abordó el tema referido a cada parte. No importa si el tema es diferente, lo que se analiza y se aprende es la forma.

\section{Aspectos formales generales}

Páginas preliminares: carátula, página de firmas (que certifica que los firmantes han valorado y aprobado la tesis), reconocimientos (no dedicatoria), índice, lista de tablas, lista de figuras, introducción. Van numeradas con números romanos.

Instrumentación básica: diagramación de la página $(3,3,3,3.5 \mathrm{~cm})$, tipo y tamaño de letra (ej. Times New Román 12), numeración (romana y arábiga), sangría (7 espacios), alineado a la izquierda (no justificado), sin espacio en blanco entre párrafos, sin uso de subrayado, cinco niveles de desagregación posibles (preferible no pasar de tres), limitado uso de negritas (titulo y subtítulos).

\section{Redacción, citado y otros aspectos}

Para cumplir disciplinadamente con una serie de recomendaciones referidas a la redacción, citado, referencias y otros, debe recurrirse a una de las propuestas que los campos de estudios adoptan internacionalmente. Estas normas orientan al asesor y al asesorado en el desarrollo de la tesis, y evita que exista un "desorden" formal entre un grupo de tesis.

Mientras que, en el Perú, mayormente, no se le ha prestado la debida atención a este aspecto; es de gran importancia en el mundo académico internacional. No se concibe que una investigación no haga uso de las normas establecidas para dicho campo de estudios.

Este afán de tener normas regulatorias para la elaboración de la tesis tiene sus orígenes desde 1597 cuando Richard White escribe once tomos de la "Historia Británica". No es materia de exponer una línea de tiempo acerca del desarrollo de estas prescripciones; pero, puede resumirse que ha existido interés por parte de los autores en establecer con claridad sus fuentes. Es decir, señalar a quien pertenece las ideas, conceptos, contenidos que se usan en una presentación especialmente escrita.

Es a comienzo el siglo XX que aparece la primera normativa sobre citado y aspectos formales en los trabajos escritos. Ese mérito le corresponde a la Universidad de Chicago que publicó a "The Chicago Manual of Style" en 1906. Actualmente, se encuentra en la edición número 16 publicada en 2010. Una variación más simple del Manual de la Universidad de Chicago es "A Manual for Writers of Research Papers, Theses, and Dissertations" de Kate L. Turabian. Este manual es muy popular entre estudiantes y fue publicado por primera vez en 1949. Actualmente, se encuentra en la octava edición publicada en 2013.

Para las áreas/carreras de Psicología, Educación y Ciencias Humanas se usa el "APA Publication Manual" (Manual de estilo de publicaciones de la American Psychological Asosociation). Fue publicado por primera vez en 1952 y actualmente se encuentra en la sexta edición publicada en el año 2009. El manual ofrece directivas, varias, para estandarizar la redacción de los textos de tesis e investigaciones en general. De manera apretada, puede decirse que orienta sobre los siguientes aspectos:

\section{Redacción}

Oraciones cortas usando conectivos: asimismo, igualmente, por lo tanto, es decir, etc.

En tercera persona (se pone el énfasis en la investigación no en el investigador).

Dar crédito a los autores, aunque sea obvio. 
Presentar diferentes perspectivas sobre referencias cuando se trata de: un punto.

Tablas y figuras

Tablas sin líneas verticales y con horizontales mínimas que fueran necesarias.

Tablas con título alineado al lado izquierdo no centrado, ubicado en la parte superior de la tabla.

Existen dos tipos de tablas: numéricas y de palabras.

El nombre único es tabla, no cuadros.

Toda representación gráfica se denomina figura (pueden ser esquemas, fotos, mapas, dibujos, gráficos, etc.).

Figuras con títulos en la parte inferior.

Citas en el texto

Citas no textuales, se reconoce el autor y el año.

Citas textuales, se reconoce el autor, año y página.

... cortas, van en el texto entre comillas (hasta 40 palabras).

... largas, van separadas y espacio simple y sin comillas.

No hace uso de pie de página.

Se presentan indicaciones completas cuando es la primera vez. Una cuestión importante al citar es cuando se recoge información de un autor que aparece mencionado por otro autor al que si se tiene acceso.

\section{Referencias}

Existe confusión entre bibliografía, referencias y referencias bibliográficas. De acuerdo a APA, bibliografía representa a todo material consultado, sea o no usado en la redacción de la investigación; en cambio, las referencias son aquellas fuentes usadas en la redacción de la investigación. Referencias bibliográficas, no existe. APA habla solo de referencias y eso tiene sentido.

APA proporciona orientaciones para elaborar las
Libros.

Revistas.

Tesis.

Exposiciones/charlas.

Diarios.

Comunicaciones formales.

Web/CD / y otros digitales.

Etc.

Igualmente, cuando se trata de:

Un autor.

Más de un autor.

Cuando es una organización

(Ministerios, instituciones, ONG, etc.).

Sin autor o fecha conocida.

Etc.

También presenta sugerencias para ser aplicadas al campo jurídico.

Así como el manual APA, existen otros, pero para otros campos disciplinarios. Por ejemplo, las "Normas Vancouver" se usan en el área de medicina y conexas (enfermería, odontología, nutrición, etc.). Para Derecho se usan APA, Chicago, el libro azul de Harvard o las normas ISO 690.

La carrera profesional no puede escapar a este mandato internacional requerido para cualquier comunicación académica. Docentes y estudiantes deben aprender y manejar estas normas, no en el momento de realizar la tesis sino desde el primer ciclo de estudios.

Para concluir esta sección se incluyen algunas precisiones:

Se pueden usar hipótesis y/o preguntas de investigación.

Las hipótesis no se prueban. Se verifican o confirman.

La hipótesis nula y la hipótesis alternativa son hipótesis estadísticas y no deben ser usadas como hipótesis de trabajo en el cuerpo de la investigación. 
Las decisiones con relación a las hipótesis estadísticas son las siguientes: rechazar Ho y fallar en rechazar Ho. No debe usarse aceptar. Es un error.

\section{EL ASESOR}

Es un compañero de ruta de la estudiante, que anima, ilustra, corrige, orienta y encamina el desarrollo de la tesis. Es un facilitador, guía, orientador, supervisor. Fernández Rincón propone varios modelos de asesor de tesis.

\section{El asesor práctico}

El asesor privilegia la acción e invita al asesorado a "aprender haciendo", "tirándose a la piscina", a ir corrigiendo aquello que sea necesario.

2. El asesor "docto"

El asesor sabe todo y es el "director de la tesis", marcará los ritmos, secuencia, tiempos, etc. Existe una relación vertical entre el asesor y asesorado.

\section{El asesor analista}

El asesor asegura que el tema de tesis sea de interés del asesorado y que se involucre en su desarrollo. El asesor "ayuda" a superar ciertos problemas. El asesorado asume todo el control.

4. El "laisser faire"

El asesorado toma todas las decisiones. El asesor está lejos y supone que el asesorado sabe cómo hacer la tesis y las normas correspondientes.

\section{El inexperto}

El asesor no tiene experiencia ni en asesoría ni en investigación. Se encuentra en proceso de formación. Su técnica es de "ensayo-error".
En general, se espera que el asesor sea especialista en el campo profesional y con gran dominio de los contenidos de la investigación. En algunas situaciones, esta labor es compartida con un asesor de contenidos y un asesor de investigación. Igualmente, que pueda promover y mantener una relación dialogal horizontal, de respeto mutuo, apoyo y comprensión. Para ello, el asesor debe formarse en el tema y auto educarse en los desarrollos continuos de la asesoría de tesis y seguir aprendiendo siempre.

\section{Funciones del Asesor}

La función general es asegurarse que el trabajo de tesis cumple con todos los requerimientos académicos y formales propios de una investigación universitaria. La función del asesor incluye la supervisión y el acompañamiento desde su inicio hasta su culminación. Para ello, debe hacer uso de los conocimientos básicos del asesor señalados anteriormente. Específicamente, se consideran como funciones del asesor (Instituto Especializado de Estudios Superiores Loyola), las siguientes:

Establecer las especificaciones del trabajo teniendo en cuenta que los objetivos que se fijan sean alcanzables en el tiempo establecido.

Orientar al estudiante durante la realización de la investigación.

Tener en agenda encuentros presenciales con el asesorado. Dichas reuniones deben respetarse y obtener resultados concretos. Establecer con el asesorado las condiciones de entrega de los avances de lainvestigación.

Emitir su opinión a la instancia correspondiente sobre el proyecto de tesis y el informe final de tesis.

Orientar al estudiante en la preparación de la defensa o sustentación del trabajo de tesis ante el jurado designado.

Durante el proceso de elaboración de la tesis, el asesor debe dar retroalimentación, ayudas, guías y sugerencias, así como puntualizar aciertos, errores, limitaciones; cambios que deben ser internalizados por el asesorado para que no se 
vuelvan a repetir. El asesor debe ser muy objetivo en sus observaciones para orientar la acción del asesorado.

Se espera que el asesor transmita el entusiasmo por la investigación científica y mantenga en alto la motivación de logro en el estudiante. Asimismo, asegure una comunicación constante y fluida con su asesorado para tener una idea clara de los avances y problemas que tiene la investigación.

\section{Características del asesor}

El asesor es un especialista en un campo del contenido y con conocimiento de las diferentes estrategias para realizar la investigación científica. Además, domina el esquema de tesis aceptado por la carrera profesional y el modelo de estilo adoptado por la respectiva escuela.

Se considera que el asesor debe mostrar "responsabilidad y compromiso, ética profesional y disciplina para acompañar procesos

\section{REFERENCIAS}

Bryce Echenique: de plagios y premios (14 nov. 2012). El país. Recuperado de http://www.cultura.elpais.com/cultura/2 012/11/13/actualidad/1352833928_446496. html

Campos, A. (2012). Orientaciones formales para la elaboración de tesis - APA 6ta. ed. Lima, Perú: UNIFÉ.

Campos, A.; Meza, C., y Muro, B. (2000). Manual para la estructuración de la tesis universitaria. 2da ed. Lima, Perú: UNIFÉ.

Diccionario Etimológico. Asesor. Recuperado de http://etimologías.dechile.net/?asesor

Edyd.com 091-La Corneja y las aves. Recuperado de http://edyd.com/Fabulas/Esopo/E91Corn ejaAves.htm

El negocio de la tesis: ¿Cuánto te cuesta, ¿cuánto te vale? (ll de noviembre de 2016). El Comercio. Recuperado de http://el comercio.pe/sociedad/lima/negociotesis-cuanto-te-cuesta-cuanto-te-valenoticia-1875159 sistemáticos" (Instituto Tecnológico de Sonora 2016).

Igualmente, debe ser asertivo, comunicativo, tolerante, ordenado y amistoso. Procurar que esta experiencia sea reconfortante para el estudiante y el asesor $y$, que, finalmente, resulte en un acercamiento valioso al método científico.

\section{CONCLUSIONES}

La labor de asesoría en las universidades es una activad laboriosa y comprometedora para los docentes. Es una manera de integrar la docencia y la investigación; en este caso, a través de los estudiantes. Para ello, los docentes deben contar con la experticia en la disciplina de la carrera profesional, así como en los enfoques metodológicos de la investigación. Asimismo, trabajar en consonancia a las regulaciones y normas académicas que adopta la institución y, en un clima altamente humano, cumplir las funciones del asesor que le corresponden.

Fernández, H. (s.f.). Asesoría de tesis y formación en investigación. Recuperado de http:// www.comie.org.mx./congreso/memoriae lectronica/v09/ponencias/atll/PREll7895 4514.pdf

Historia de Ibería Vieja (2013). Luces y sombras de la Roma imperial: vida del poeta Marcial. Recuperado de http://www.historia deiberiavieja.com/secciones/historiaantigua/luces-sombras-roma-imperialvida-del-poeta-marcial

IDL - Reporteros (2013). Tres por uno: caso del Juez Hinostroza Pariachi. Recuperado de http://www.idl-reporteros.pe/tres-poruno/

Instituto Especializado de Estudios Superiores Loyola. Instructivo del asesor de tesis. Recuperado de http://superior.ipl.edu.do /uploads/.../instructivo\%20del\%20asesor $\% 20 d e \% 20$ tesis.docx 
Instituto Tecnológico de Sonora (2016). Asesores, revisores y sínodos. Características del asesor y asesorado. Recuperado de http://www. itson.mx/Egresados/titulacion/Paginas /asesores-revisores-y-sinodos.aspx

Los cuatro casos de plagio más escandalosos de la política mundial (27 enero 2016). La República. Recuperado de http://www. larepublica.pe/mundo/736830-loscuatro-casos-de-plagio-masescandalosos-de-la-política-mundial

Retiran por plagio el doctorado a la ex vicepresidenta del Parlamento Europeo (15 junio 2011). ABC.es. Recuperado de http://www.abc.es/20110615/internacion al/abci-exvvicepresidenta-parlamentoeuropeo-doctorado_2011061511610.html
RRP (2016). Indecopi multó a Cesar Acuña por plagio de libro y tesis doctoral. Recuperado de http://ww.rpp.pe/economia/economi/ind ecopi-multo-a-cesar-acuna-por-plagiode-libro-y-tesis-doctoral-noticia-993039.

Universidad confirma plagio en tesis del presidente de México (29 agosto 2016). Telesur. Recuperado de http://www. telesurtv.net/news/Universidadconfirma-plagio-en-tesis-del-presidentede-mexico-20160829.htlml

Universidad Femenina del Sagrado Corazón, Escuela de Posgrado (2015). Estructura de la tesis de Maestría y Doctorado. Lima, Perú: Autor.

WordReference.com Sinónimos de asesoramiento. Recuperado de http://www. word reference.com/sinonimos/asesoramiento 